\title{
Staged Hybrid Repair for Acute Type B Aortic Dissection of Right-Sided Aortic Arch
}

Takanori Shibukawa*, Takashi Yamauchi and Takafumi Masai

Department of Cardiovascular Surgery, Sakurabashi Watanabe Hospital, 2-4-32 Umeda, Kita-ku, Osaka 530-0001, Japan

\begin{abstract}
Right-sided aortic arch is rare and the reported type B aortic dissection with this pathology has been limited. We report a case of staged hybrid surgical repair using short frozen elephant trunk for this pathology. The computed tomography after 3 month confirmed the shrinkage of aneurysm diameter and thrombosis of false lumen.
\end{abstract}

Keywords: Type B dissection; Right aortic arch; Frozen elephant trunk; Endovascular repair

\section{Introduction}

Right-sided aortic arch (RAA) is an anatomic variant occurring in approximately $0.05-0.1 \%$ of the population. Only around 10 surgical cases of acute aortic type B dissection of RAA have been reported [13] (Table 1). We report one case of hybrid repair using short frozen elephant trunk (FET) for acute type B aortic dissection involving RAA.

\section{Case Report}

A 73-year-old male presented with severe back pain. A computed tomography (CT) scan demonstrated an RAA with a Kommerell's diverticulum (KD). The ordering of the aortic branches was as followings; left common carotid artery (LCCA), right common carotid artery (RCCA), right subclavian artery (RSCA) and aberrant left subclavian artery (ALSCA) arising from KD (Figure 1). A dissection extended from the origin of RCCA to left common iliac artery. The proximal tear was observed just distal of KD. The maximum diameter of the distal arch was $40 \mathrm{~mm}$ at the onset. The patient was managed medically, however, a CT-scan after one week revealed rapid enlargement of the distal aortic arch from 40 to $51 \mathrm{~mm}$. Therefore, we planned surgical intervention. Our planned surgical strategy was to cover the proximal tear by thoracic stent graft, which is considered to have less possibility of paraplegia and respiratory dysfunction. The optimal proximal landing zone was proximal to RCCA. In order to provide secure and sufficient proximal landing, total debranching or replacement of the ascending aorta and arch with ET was necessary. We employed graft replacement with ET. We considered the FET better than non-FET because FET has less possibility to kink in steep aortic arch, which was the characteristic of right-sided aortic arch and makes it easy to perform following thoracic endovascular repair (TEVAR). The aortic diameter of proximal landing was $27 \mathrm{~mm}$ and that of distal was $21 \mathrm{~mm}$. Therefore, tapered stent graft seemed desirable to close the proximal tear. Then, the staged surgical treatment was decided to perform with replacement of the ascending aorta and arch with short FET via a median sternotomy in order to provide secure and sufficient proximal landing for following TEVAR with tapered stent graft to cover the proximal tear.

The bilateral axillary arteries ( $\mathrm{AxA})$ were exposed and anastomosed to $9 \mathrm{~mm}$ J graft (Tokyo, Japan Lifeline). After the circulatory arrest was introduced, the RSCA was ligated at the origin, and a selective antegrade cerebral perfusion was established. Open distal arch anastomosis was performed just distal to the origin of LCCA using four-branched J graft $26 \times 11 \times 9 \times 9 \mathrm{~mm}$ graft (Japan Lifeline, Tokyo,
Japan). Before anastomosis, 27-60 mm J graft open stent graft (Japan Lifeline, Tokyo, Japan lifeline) was inserted into the true lumen of aortic arch. The LCCA, RCCA and two graft anastomosed to right AxA were anastomosed to the branches of the graft.

Scheduled TEVAR was performed 7 days after the first surgery. A conformable GORE TAG thoracic endoprosthesis (WL Gore and Associates $)(31 \times 26 \times 100 \mathrm{~mm}$ and $34 \times 34 \times 150 \mathrm{~mm})$ was inserted via femoral artery to cover the proximal tear with proximal end at distal anastomosis site of four-branched graft. The true lumen of KD was coiled with Interlock (Boston scientific Japan, Tokyo, Japan) and MReye (Cook Japan, Tokyo, Japan). We locked the AMPLATZER vascular plug (St. Jude Medical) to occlude the ALSCA.

The postoperative course was uneventful. Neither neurological problems nor hoarseness was detected. Postoperative CT demonstrated that false lumen was almost thrombosed and the KD was completely excluded by the endograft and vascular plug (Figure 2). The diameter of distal arch shrunken from $51 \mathrm{~mm}$ to $32 \mathrm{~mm}$ after 3 months of the procedure (Figure 3).

\section{Discussion}

In the surgical treatment of type B aortic dissection involving RAA, single GR through right thoracotomy, usually employed, is considered to be radical therapy. However, neurological deficit such as paraplegia or recurrent nerve palsy and respiratory distress are not negligible. On the other hand, TEVAR is doubtless less invasive. Nevertheless, long term result remains unknown. Moreover "steep aortic arch", which is one of the characteristic of RAA, might result in increasing risk of kinking of stent graft or retrograde type A dissection [4]. Hybrid procedure, firstly total arch replacement with elephant trunk (ET) followed by TEVAR and single stage repair using FET, have also been reported [5]. However, single stage repair using long FET or ET might be accompanied with the risk of spinal cord injury.

*Corresponding author: Takanori Shibukawa, MD, PhD, Department of Cardiovascular Surgery, Sakurabashi Watanabe Hospital, 2-4-32 Umeda, Kita-ku Osaka 530-0001, Japan, Tel: +81-6-6341-8651; Fax: +81-6-6341-0785; E-mail: eminori4124@yahoo.co.jp

Received May 20, 2017; Accepted June 01, 2017; Published June 07, 2017

Citation: Shibukawa T, Yamauchi T, Masai T (2017) Staged Hybrid Repair for Acute Type B Aortic Dissection of Right-Sided Aortic Arch. J Vasc Med Surg 5: 315 doi: 10.4172/2329-6925.1000315

Copyright: (c) 2017 Shibukawa T, et al. This is an open-access article distributed under the terms of the Creative Commons Attribution License, which permits unrestricted use, distribution, and reproduction in any medium, provided the original author and source are credited. 


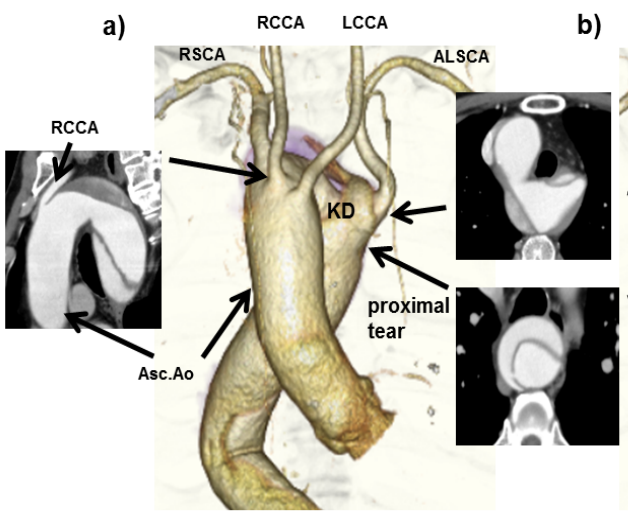

anterior -view

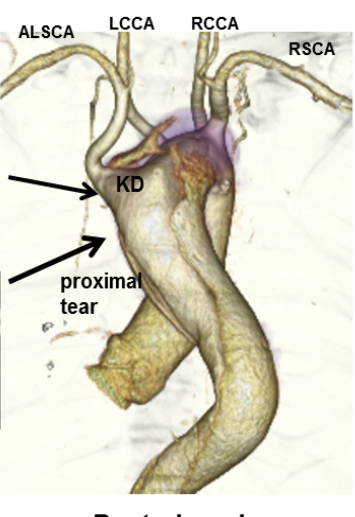

Posterior -view

a) anterior view, b) posterior view.

KD: Kommerell's Diverticulum; LCCA: Left Common Carotid Artery; RCCA: Right Common Carotid Artery; RSCA: Right Subclavian Artery; ALSCA: Aberrant Left Subclavian Artery Arising

Figure 1: Preoperative CT. Acute type B aortic dissection of right-sided aortic arch

\begin{tabular}{|c|c|c|c|c|c|c|c|c|c|c|c|c|}
\hline & & Year & Age & Gender & $\begin{array}{l}\text { Classification/ } \\
\text { of Raa (Stewart } \\
\text { Edwards) }\end{array}$ & Location of Entry & Op Indication & $\begin{array}{l}\text { Surgical } \\
\text { Procedure }\end{array}$ & $\begin{array}{l}\text { Resection of } \\
\text { KD }\end{array}$ & Approach & Prognosis & $\begin{array}{l}\text { Follow } \\
\text { Up }\end{array}$ \\
\hline 1 & Floten & 1984 & 64 & Male & IIIB & $\begin{array}{l}\text { Distal to ALSA } \\
\text { distal of KD }\end{array}$ & Persistent Dyspnea & $\begin{array}{l}\text { extraanatomical } \\
\text { bypass }\end{array}$ & Non-resected & $\begin{array}{l}\text { Bilateral } \\
\text { thoracotomy }\end{array}$ & Alive & $16 \mathrm{~m}$ \\
\hline 2 & Sugita & 1990 & 64 & Male & IIIB & Proximal of ALSA & Rupture & $\begin{array}{l}\text { entry closure and } \\
\text { reinforcement of } \\
\text { anastomosis site }\end{array}$ & Non-resected & $\begin{array}{l}\text { Left } \\
\text { thoracotomy }\end{array}$ & Alive & N.D \\
\hline 3 & Masiello & 1996 & 48 & Male & IIIB & N.D & $\begin{array}{l}\text { Enlargement of } \\
\text { aneurysm }\end{array}$ & $\begin{array}{l}\text { GR of distal arch } \\
\text { and desaorta }\end{array}$ & Resected & $\begin{array}{l}\text { Right } \\
\text { thoracotomy }\end{array}$ & Alive & N.D \\
\hline 4 & Kim & 2010 & 47 & Male & IIIB & $\begin{array}{l}\text { Lower thoracic } \\
\text { aorta }\end{array}$ & $\begin{array}{l}\text { Enlargement of } \\
\text { aneurysm, impending } \\
\text { rupture }\end{array}$ & GR of des aorta & Non-resected & $\begin{array}{l}\text { Right } \\
\text { thoracotomy }\end{array}$ & Alive & $6 m$ \\
\hline 5 & Kim & 2012 & 32 & Male & IIIB & Arch & Left arm malperfusion & $\begin{array}{l}\text { total arch } \\
\text { replacement }\end{array}$ & Resected & Median & $\begin{array}{l}\text { Temporary } \\
\text { parapalesis }\end{array}$ & N.D \\
\hline 6 & Croccia & 2012 & 62 & Male & IIIA & N.D & $\begin{array}{l}\text { Enlargement of } \\
\text { aneurysm }\end{array}$ & TEVAR & & & Alive & 2 year \\
\hline 7 & Zhou & 2013 & 65 & Male & IIIB & N.D & $\begin{array}{l}\text { Enlargement of } \\
\text { aneurysm }(52 \mathrm{~mm}) \mathrm{t}\end{array}$ & TEVAR & Non-excluded & & Alive & $18 \mathrm{M}$ \\
\hline 8 & $\mathrm{Ma}$ & 2013 & 42 & Male & IIIA & Arch & $\begin{array}{l}\text { Malperfusion of lower } \\
\text { extremity }\end{array}$ & $\begin{array}{l}\text { TEVAR with } \\
\text { chimney } \\
\text { technique }\end{array}$ & & & Alive & $1 \mathrm{M}$ \\
\hline 9 & Hsu & 2015 & 47 & Male & IIIB & Just below of KD & Malperfusion & $\begin{array}{l}\text { TEVAR with } \\
\text { chimney } \\
\text { technique }\end{array}$ & Excluded & & Alive & ND \\
\hline 10 & $\begin{array}{l}\text { Present } \\
\text { case }\end{array}$ & 2016 & 73 & Male & IIIB & Just below of KD & $\begin{array}{l}\text { Enlargement of } \\
\text { aneurysm }\end{array}$ & $\begin{array}{l}\text { 1. Total arch } \\
\text { replacement with } \\
\text { frozen elephant } \\
\text { trunk, } 2 \text {. TEVAR }\end{array}$ & $\begin{array}{l}\text { Excluded by } \\
\text { endograft and } \\
\text { plug }\end{array}$ & Median & Alive & $10 \mathrm{M}$ \\
\hline
\end{tabular}

ALSA: Aberrant Left Subclavian Artery; KD: Kommerell's Diverticulum; GR: Graft Replacement; TEVAR: Thoracic Endovascular Aortic Repair

Table 1: The reported cases of surgical treatment for acute type $B$ dissection $[2,3]$.

Short FET from the origin of aortic arch, as in the present case, has not been reported to be employed, followed by TEVAR in this pathology. We believe that the merit of short FET for this pathology is considered as followings; firstly, the risk of kinking of graft is considered to be low compared with prosthetic graft, especially in cases of RAA whose curve of aortic arch is generally steep. Secondly, the following TEVAR is technically easy to be performed providing the secure proximal landing zone. The short FET is less frequently accompanied with spinal cord injury. In addition, the distal anastomosis can be performed more proximal in first operation, resulting in prevention from bleeding and recurrent nerve paralysis.

\section{Conclusion}

We report a rare surgical case of acute type B DAA in RAA using short FET followed by TEVAR. This hybrid procedure might be associated with less likely spinal cord injury and recurrent nerve palsy and provide the sufficient proximal landing zone for following TEVAR. Long-term follow up should be necessary for validation of this procedure.

\section{Disclosure Statement}

All authors have no conflict of interest. 
a)

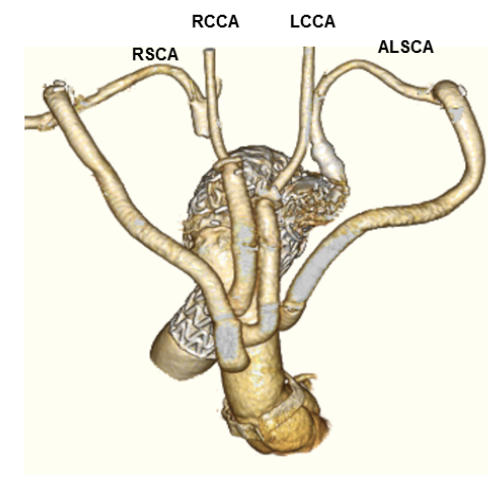

anterior -view b)

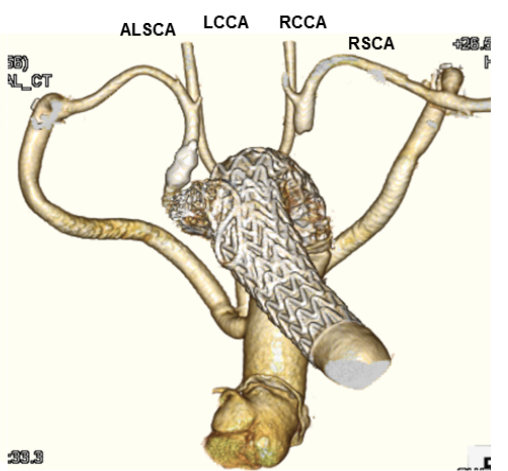

Posterior -view

Figure 2: Postoperative CT a) anterior view b) posterior view.

a)

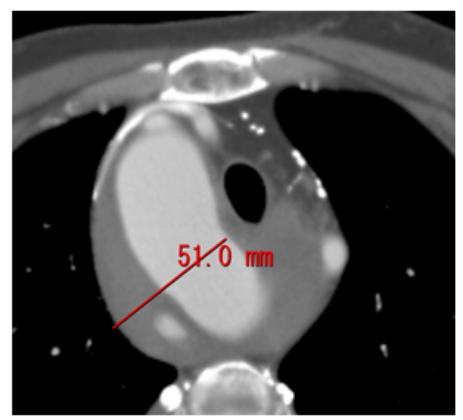

Pre Op distal arch b)

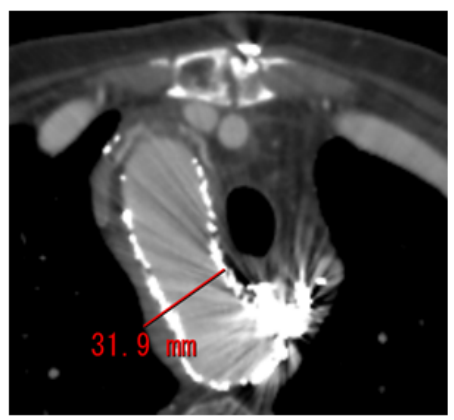

Post Op distal arch

Figure 3: The diameter of distal arch shrunken from $51 \mathrm{~mm}$ (a) to $32 \mathrm{~mm}$ (b) after 3 months of the procedure.

\section{References}

1. Barr JG, Sepehripour AH, Jarral OA, Tsipas P, Kokotsakis J, et al. (2016) $A$ review of the surgical management of right-sided aortic arch aneurysms. Interactive Cardiovascular and Thoracic Surgery 23:156-162.

2. Croccia MG, Levantino M,Cioni R, Bortolotti U (2012) Endovascular stenting for type $\mathrm{B}$ dissection involving a right-sided aortic arch. Interactive Cardiovascular and Thoracic Surgery. 15: 304-306.

3. Zhou W (2013) Endovascular repair of a type B aortic dissection with a rightsided aortic arch: case report. J Cardiothorac Surg 8:18.
4. Eggebrecht H, Thompson M, Rousseau H, Czerny M, Lönn L, et al. (2009) Retrograde ascending aortic dissection during or after thoracic aortic stent graft placement: Insight from the european registry on endovascular aortic repair complications. Circulation 120: S276-281.

5. Kozlov BN, Panfilov DS, Saushkin VV, Shipulin VM (2016) Hybrid treatment of aortic dissection associated with kommerell's diverticulum. Interactive Cardiovascular and Thoracic Surgery 22: 854-855. 